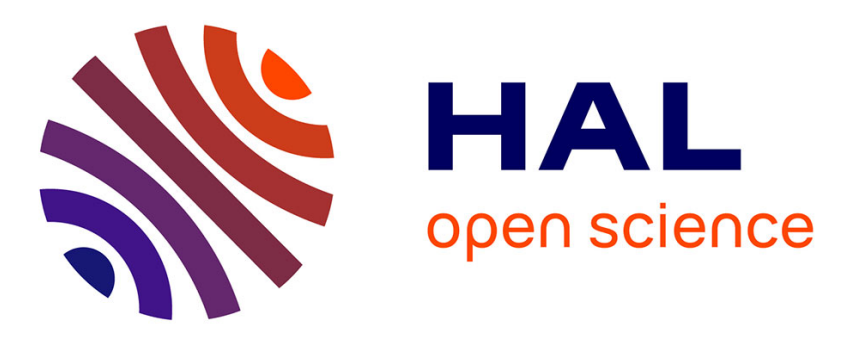

\title{
Estimation of Kinetic Parameters Involved in Solid-Phase Immunoassays by Affinity Chromatography
}

Maëlenn Robin, Mélaz Tayakout-Fayolle, Isabelle Pitault, Christian Jallut, Laurent Drazek

\section{- To cite this version:}

Maëlenn Robin, Mélaz Tayakout-Fayolle, Isabelle Pitault, Christian Jallut, Laurent Drazek. Estimation of Kinetic Parameters Involved in Solid-Phase Immunoassays by Affinity Chromatography. Industrial and engineering chemistry research, 2020, 59 (24), pp.11113-11124. 10.1021/acs.iecr.0c00922 . hal-03000218

\section{HAL Id: hal-03000218 \\ https://hal.science/hal-03000218}

Submitted on 11 Nov 2020

HAL is a multi-disciplinary open access archive for the deposit and dissemination of scientific research documents, whether they are published or not. The documents may come from teaching and research institutions in France or abroad, or from public or private research centers.
L'archive ouverte pluridisciplinaire HAL, est destinée au dépôt et à la diffusion de documents scientifiques de niveau recherche, publiés ou non, émanant des établissements d'enseignement et de recherche français ou étrangers, des laboratoires publics ou privés. 


\title{
Estimation of kinetic parameters involved in
}

\section{solid-phase immunoassays by affinity chromatography.}

Maëlenn Robin, ${ }^{*, \dagger}$, Mélaz Tayakout-Fayolle, ${ }^{*} \dagger$ Isabelle Pitault, ${ }^{\dagger}$ Christian Jallut, ${ }^{\dagger}$ and Laurent Drazek

†Univ Lyon, Université Claude Bernard Lyon 1, CNRS, LAGEPP UMR 5007, 43 boulevard du 11 novembre 1918, F-69100, Villeurbanne, France

$\$$ \$ioMérieux SA, Biomathematics departement, 5 rue des Berges, 38024 Grenoble, France

『bioMérieux SA, Immuno Innovation Department, 376 chemin de l'Orme, 69280 Marcy l'Etoile, France

E-mail: maelenn.robin@biomerieux.com; melaz.tayakout-fayolle@univ-lyon1.fr

\begin{abstract}
Solid-phase immunoassays are based on the use of appropriate ligands and solid supports. In order to investigate the influence of the solid support on the interaction process, a predictive model of antibody/antigen interaction has been developed.

Parameters of this model are estimated from dedicated experiments like Surface Plasmon Resonance and affinity chromatography by using least squares optimization techniques. Affinity chromatography is of great interest because, unlike Surface Plasmon Resonance, it enables estimation of kinetic parameters on any solid support used in immunoassays.
\end{abstract}

The approach described above is illustrated through the kinetic modeling of the in- 
teractions between Free Prostate-Specific Antigen and immobilized anti-Free ProstateSpecific Antigen antibody.

Keywords: Immunoassays, Kinetic modeling, Surface Plasmon Resonance, Affinity chromatography, Parameter estimation.

\section{Introduction}

Immunoassay technique is one of the most efficient and reliable tools used for in vitro diagnostics to detect the presence or measure the concentration of a molecule of interest in a biological sample. It mainly relies on the specific recognition between an antigen and an antibody ${ }^{1}$ In solid-phase immunoassays, ligands (usually antibodies) specific to the analytes to be detected (usually antigens) are immobilized on a solid surface to adsorb the analytes of interest and separate them from the rest of the biological sample components. During solid-phase immunoassay design, sensitivity, specificity and time-to-result need to be optimized by the choice of appropriate ligands to specifically capture the analyte of interest as well as the solid support (material and design) or the flow-rate of the liquid which contains the molecules to be detected. Classically, these choices are made empirically. ${ }^{[2}$ Better understanding and predicting the complex molecular interactions that occur in the different steps of a diagnostic immunoassay could be useful in order to: identify the critical parameters of immunoassays and improve the immunoassays. $\frac{3}{3}$ The objectives of this work are: to develop a predictive model of antibody/antigen interaction kinetics in immunoassays; to build an experimental tool to study antibody/antigen interactions and validate the predictive model; to estimate model parameters characterizing antigen/antibody interaction kinetics from ex-

perimental curves by using least squares optimization technique. This approach is supported by the fact that the characterization of antigen/antibody interaction kinetics plays a major role for the selection of the best molecules for immunoassays. 214 
Several analytical techniques can be used to study the kinetics of biological interactions. Stopped-flow analysis and capillary electrophoresis allow to examine the kinetics of biological interactions in solution while Surface Plasmon Resonance (SPR) and affinity chromatography allow to investigate the interactions between an analyte in solution and an immobilized ligand. $\stackrel{8}{ }$ Given that antibody conformation can be modified when immobilized, $\stackrel{219}{\Perp}$ SPR and affinity chromatography are the most appropriate methods to study interactions occurring in solid-phase immunoassays. Although SPR is generally considered as the gold standard to determine kinetic parameters of protein interactions,,$\frac{315}{18}$ in this study affinity chromatography has also been used. Unlike SPR, this separation-based approach makes possible the use of almost any support or surface. ${ }^{8}$ The possibility to immobilize ligands on solid supports is of great interest for this study because antibody conformation can change depending on the properties of the support where it is immobilized $\frac{9111 \mid 12[19 \mid 20}{2}$ which affect their affinity with antigen. $\stackrel{221}{21}$ It has been reported in literature that the support used for ligand immobilization can affect the kinetics of protein-protein interaction. $\frac{15122}{2}$

In this study, kinetic parameters characterizing the interactions between Free ProstateSpecific Antigen (FPSA) and an anti-Free Prostate-Specific Antigen (anti-FPSA) antibody immobilized on two different supports are determined with SPR and affinity chromatography experiments. Results obtained with the two tools are compared.

A commercial system named Biacore ${ }^{\mathrm{TM}}$ is used for SPR measurements. SPR is a decrease of reflected light intensity that occurs for a particular reflection angle (SPR angle) when incident polarized light hits a thin metal film (gold for example) between two media of different refractive indexes. SPR angle depends on the refractive index of the second medium. Biacore $^{\mathrm{TM}}$ systems use a sensor chip composed of a glass slide (first medium) coated with a thin gold film. Ligands (second medium) are immobilized on the sensor surface thanks to a layer of flexible polymer for example. ${ }^{23}$ When the liquid containing analytes flows over the sensor surface, analytes bind with ligands, the refractive index of the second media is modi- 
fied and so is the SPR angle. Concentration of analytes bound to ligands can be correlated to SPR angle shifts. $\frac{24}{24}$ Thus, by monitoring changes in the SPR angle as a function of time, the Biacore ${ }^{\mathrm{TM}}$ system enables to follow in real-time the concentration of analyte bound to the ligands without the need of any fluorescent, electro-chemical or radioactive label. This information is then used to extract kinetic parameters characterizing interactions between ligands and analytes by assuming that the analyte concentration in the liquid flow remains constant and uniform.

For affinity chromatography experiments, an in-house tool is used. Antibodies are immobilized on a packed bed of non-porous pellets made of a polymeric material and placed in a column. Then, a solution containing antigens specific to the immobilized antibodies is injected at the inlet of the system. Outlet antigen concentration is measured to obtain breakthrough curves. In parallel, a kinetic model of the experimental system that takes into account mass transfer processes as well as adsorption and desorption steps has been developed and implemented in MATLAB ${ }^{\circledR}$ and solved using finite-difference method. Parameters of the model are estimated by minimizing the difference between experimental and simulated data with nonlinear least-squares fitting method for different flow rates and inlet concentrations.

\section{Material and methods}

\section{Biological model}

In this work, the analyte used is FPSA. FPSA is a glycoprotein which has a molecular weight of 30,000 Daltons. ${ }^{25}$ Prostate-Specific Antigen (PSA) is principally produced by the glandular epithelium of the prostate, and is secreted in the seminal fluid. PSA is also present in blood under three main forms. ${ }^{2627}$ The main immunoreactive form is PSA bound to Alpha1-antichymotrypsin. FPSA is the other immunoreactive form. The third main form of PSA cannot be detected by enzyme immunoassay tests. PSA levels rise in prostatic pathologies 
such as Benign Prostatic Hyperplasia (BPH) or prostate cancer ${ }^{28}$ The percentage of FPSA in serum is significantly higher in patients with BPH than in patients with prostate cancer. 29 Thus, the ratio of FPSA concentration over total PSA concentration can help to differentiate between BPH and prostate cancer.

Antibodies anti-FPSA are used as ligands in our experiment.

\section{Surface Plasmon Resonance experiments}

SPR experiments are performed using the Biacore $^{\mathrm{TM}}$ T100 optical biosensor (GE Healthcare Bio-Sciences AB, Uppsala, Sweden). Biacore ${ }^{\mathrm{TM}}$ data is interpreted with GE Healthcare software Biacore T100 Evaluation Software version 2.0.2. The Sensor Chip CM5 (GE Healthcare, reference BR100530) is used. Carboxymethylated dextran is covalently attached to the gold surface of this sensor chip. Polyclonal rabbit anti-mouse immunoglobulin antibodies from Mouse Antibody Capture Kit (GE Healthcare, reference BR100838) are immobilized on carboxymethylated dextran. Dilutions are performed with HBS-EP+ Buffer 10x (0.1 M HEPES, 1.5 M NaCl, 0.03 M EDTA and $0.5 \%$ v/v Surfactant P20, GE Healthcare, reference BR100826). First liquid phase antigen concentration needs to be determined and then kinetic experiments are performed, both at $310 \mathrm{~K}$.

\section{Antigen concentration determination}

In order to determine the concentration of the antigen solution, several cycles are performed under mass transport limitation conditions. The first step of each cycle consists in a 180 second injection of anti-FPSA antibodies at a concentration of $300 \mu \mathrm{g} / \mathrm{mL}$ at $10 \mu \mathrm{L} / \mathrm{min}$. Anti-FPSA antibodies are captured by the rabbit anti-mouse immunoglobulin antibodies. Then FPSA is injected during 36s at 5 or $100 \mu \mathrm{L} / \mathrm{min}$ (association phase) and then desorb during $5 \mathrm{~s}$ (dissociation phase) at the same flow rate. Finally, sensor chip is regenerated with HCL $50 \mathrm{mM}$ injected at $10 \mu \mathrm{L} / \mathrm{min}$ during 120s. Different dilutions of antigens are tested to determine which dilution is optimal to be under mass transport limitation (linear curve 
during association phase). At optimal antigen dilution, 4 cycles are performed with FPSA injection at $5 \mu \mathrm{L} / \mathrm{min}$ and 4 cycles are performed with FPSA injection at $100 \mu \mathrm{L} / \mathrm{min}$. 8 blank cycles (with no anti-FPSA antibodies immobilized) are also performed with the same parameters as the sample cycles. After blank subtraction, "Calibration Free Concentration Assay" fits the 1:1 interaction kinetic model to the data, with mass transport parameters calculated from the supplied diffusion coefficient and molecular weight, and with the analyte concentration set as a globally fitted variable. .30

\section{Kinetic parameter determination}

Cycles of three steps are also performed for kinetic experiments but not under mass transport limitation. During the first cycle step anti-FPSA antibodies are injected at a lower concentration, $2 \mu \mathrm{g} / \mathrm{mL}$, during $180 \mathrm{~s}$ at $10 \mu \mathrm{L} / \mathrm{min}$ to be captured by the rabbit anti-mouse immunoglobulin antibodies. Then FPSA is injected at different concentrations (0.625 nM, $1.25 \mathrm{nM}, 2.5 \mathrm{nM}, 5 \mathrm{nM}, 10 \mathrm{nM}$, and $20 \mathrm{nM}$ ) during 120s (association phase) and then desorb during 600s (dissociation phase) at $30 \mu \mathrm{L} / \mathrm{min}$. Finally, sensor chip is regenerated with HCL $50 \mathrm{mM}$ injected at $10 \mu \mathrm{L} / \mathrm{min}$ during 120s. 6 blank cycles (with no anti-FPSA antibodies immobilized) are also performed with the same parameters as the sample cycles. After blank subtraction, "Surface-bound kinetics" option of Biacore T100 evaluation software is used to extract kinetic parameters by fitting a 1:1 binding model to the data. $\underline{30}$

\section{Affinity chromatography experiments}

\section{Description of affinity chromatography experimental set-up}

In affinity chromatography, a ligand is immobilized on a chromatographic support in an affinity column while an analyte, complementary to the ligand and diluted in a fluid carrier, is injected at a constant concentration at the inlet of the column at time $t=0$ (step input). Analyte concentration is measured at the outlet of the column and elution curves can be

plotted (analyte concentration versus time or versus volume of mobile phase that has crossed 
the column from $t=0$ ). The observed elution profile or breakthrough curve for the injected analyte is then used to extract information on the kinetics of interaction between analyte and ligand and mass transfer $\stackrel{31+34}{[34}$ this study, as affinity chromatograph, ÄKTAprime plus from GE Healthcare is used. ÄKTAprime plus original fluid path has been modified (see Figure 1). The tubing characteristics are given in Figure 1 and in Table 1.

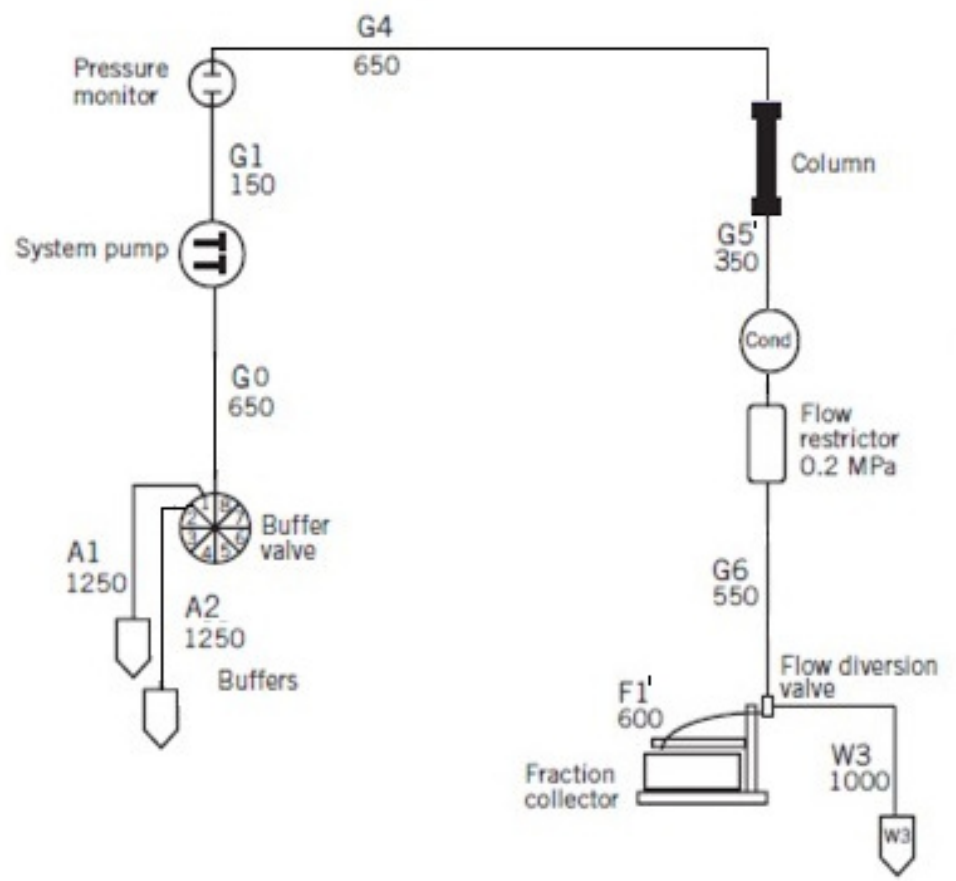

Figure 1: Schema representing the ÄKTAprime plus modified fluid path (schema adapted from ÄKTAprime plus user manual - GE Healthcare). The length of tubing is directly reprensented in millimeters in the schema.

Table 1: Characteristics of tubing in the schema in Figure 1

\begin{tabular}{lll}
$\begin{array}{l}\text { Tubing } \\
\text { designation }\end{array}$ & $\begin{array}{l}\text { Tubing } \\
\text { i.d., o.d. }\end{array}$ & Material \\
\hline A1, A2 & $3.2 \mathrm{~mm}, 3 / 16 "$ & Teflon \\
W3 & $1.0 \mathrm{~mm}, 1 / 16 "$ & PEEK \\
Gx .F1 & $0.75 \mathrm{~mm}, 1 / 16 "$ & PEEK \\
Union, & i.d. $1 / 16 "$ & PEEK \\
male/male & &
\end{tabular}

Analytes are antigens, while ligands are antibodies. The material chosen for the chro- 
matographic support in the column is Styrene Butadiene Copolymer (SBC), commercialized as $2 \mathrm{~mm}$ radius granules. Chromatography column length is $5 \mathrm{~cm}$ and column inner diameter is $4 \mathrm{~mm}$. Chromatographic support is introduced either as 2mm-radius granules either as smaller particles obtained by grinding the $2 \mathrm{~mm}$-radius granules. $\mathrm{SBC}$ is ground with a cryogenic grinder to prevent it from melting. Then it is sieved with a stack of 4 sieves with different mesh sizes: $630 \mu \mathrm{m}$ (at the top of the stack), $500 \mu \mathrm{m}, 400 \mu \mathrm{m}$ and $250 \mu \mathrm{m}$ (at the bottom of the stack). Particles retained by the $250 \mu \mathrm{m}$ mesh size are collected to fill the chromatography column. Particle size analysis showed that distribution is monomodal and that the mean diameter for the number distribution is $314 \mu \mathrm{m}$ and the standard deviation is $94 \mu \mathrm{m}$. Brunauer-Emmett-Teller (BET) method ${ }^{35}$ showed that SBC particles are non-porous.

\section{Affinity chromatography experimental protocol}

Styrene Butadiene Copolymer functionalization The chromatography column is filled with SBC particles and placed in ÄKTAprime plus fluid path as shown in Figure 1. Functionalization is then performed. SBC functionalization consists in the immobilization of antibodies with an antibody solution called sensitization solution (antibody concentration: $15 \mu \mathrm{g} / \mathrm{mL})$.

Inlet and outlet tubes are immersed in the same bottle of sensitization solution. Sensitization solution is continuously injected in the system at a flow rate of $1 \mathrm{~mL} / \mathrm{min}$ during 18 to 24 hours.

Passivation Two passivation steps are performed. The first passivation step is performed without chromatography column and before functionalization step. The aim is to adsorb

Bovine Serum Albumin (BSA) until surface saturation in order to prevent later antibody and antigen adsorption in the system. The second passivation step is performed with chromatography column after SBC functionalization. This step is performed once antibodies 
have been immobilized on SBC. It aims at stabilizing antibody immobilization. It also aims at adsorbing BSA on SBC surfaces where no antibody has been immobilized. This will prevent antigens from adsorbing on SBC free surfaces and ensure that captured antigens are not trapped on SBC but only by antibodies.

Passivation is performed with ÄKTAprime plus. Inlet and outlet tubes are immersed in the same bottle of passivation solution, a solution containing BSA and provided by bioMérieux. Passivation solution is continuously injected in the system at a flow rate of $1 \mathrm{~mL} /$ min during 18 to 24 hours.

Breakthrough and purge experiments Chromatography experiments have been performed by using the modified fluid path (see Figure 1).

Position 1 of the ÄKTAprime plus buffer valve is connected with a tube to a bottle filled with the antigen diluent buffer. Position 2 of the ÄKTAprime plus buffer valve is connected with a tube to a bottle filled with PSA diluted in the diluent at a concentration corresponding between 8 and 10ng/mL. First, the diluent buffer is continuously injected in the system, the buffer valve being set in position 1 . Then, the buffer valve is switched from position 1 to position 2. It is the breakthrough: antigens are continuously injected in the system and will be captured by the antibodies immobilized on the SBC particles. Then, the buffer valve is switched from position 2 back to position 1. It is the purge: antigens are no longer being injected in the system and desorb from the antibodies. During experiments, all reagents and the column are immersed in water maintained at $310 \mathrm{~K}$ by a thermostatic bath.

Antigen concentration determination During breakthrough and purge, thanks to the fraction collector of ÄKTAprime plus (see Figure 1), fractions of $0.5 \mathrm{~mL}$ are collected at the outlet of the column at defined sample times. FPSA concentration of each fraction is then measured with the VIDAS ${ }^{\circledR}$ instrument and the FPSA assay kit (bioMérieux reference 30 440). 


\section{Residence time distribution experiments (RTD)}

In order to characterize the hydrodynamics of the column and of the tubing before the column, RTD experiments have been performed. The tracer used in the RTD experiments is $\mathrm{NaCl}$ and is diluted in the buffer used to dilute the antigen in the breakthrough experiments at a concentration of $100 \mathrm{~g} / \mathrm{L}$. Position 1 of the ÄKTAprime plus buffer valve is connected with a tube to a bottle filled with the diluent. Position 2 of the ÄKTAprime plus buffer valve is connected with a tube to a bottle filled with $\mathrm{NaCl}$ diluted in the diluent buffer (see Figure 1). A volume of $0.1 \mathrm{~mL}$ of $\mathrm{NaCl}$ solution is injected in the system by switching the buffer valve from position 1 to position 2 and then switching the buffer valve from position 2 back to position 1 . Conductivity is measured at the outlet to monitor $\mathrm{NaCl}$ concentration (conductivity sensor represented by a circle labeled with 'cond' in Figure 1). RTD experiments have been performed:

- without chromatography column

The aim is to characterize the flow before the column. Four flow rates have been used: $0.5 \mathrm{~mL} / \mathrm{min}, 1 \mathrm{~mL} / \mathrm{min}, 2 \mathrm{~mL} / \mathrm{min}$ and $5 \mathrm{~mL} / \mathrm{min}$.

- with chromatography column filled with ground SBC particles The aim is to characterize the column hydrodynamics with ground particles. Three flow rates have been used: $0.5 \mathrm{~mL} / \mathrm{min}, 1 \mathrm{~mL} / \mathrm{min}$ and $5 \mathrm{~mL} / \mathrm{min}$.

- with chromatography column filled with not ground SBC particles The aim is to characterize the column hydrodynamics with not ground particles. Two flow rates have been used: $0.5 \mathrm{~mL} / \mathrm{min}$ and $1 \mathrm{~mL} / \mathrm{min}$. 


\section{Mathematical modeling and parameter estimation strat-}

egy

\section{Mathematical model of the column}

To describe the binding of analytes (antigens) with ligands (antibodies) immobilized on non-porous particles to form antigen/antibody complexes, a mathematical model has been developed. This model, which is one dimensional and which supposes spherical particles is detailed in this section. First the analyte mass balances for the fluid and the solid phase will be detailed. Then the models used for hydrodynamics, mass transfer and kinetics will be exposed. Finally, the strategies for equation treatment, model implementation and parameter estimation will be explained.

\section{Analyte mass balances}

Mass balance in the fluid phase The mass balance of free analyte in the fluid phase can be written:

$$
\frac{\partial N(z, t)}{\partial z}+\frac{\partial C_{f}(z, t)}{\partial t}+N_{e c h}(z, t) \frac{3}{R} \frac{1-\epsilon}{\epsilon}=0
$$

with $N\left(\right.$ mol. $\left.m^{-2} . s^{-1}\right)$ the flux of analyte along the $z$ axis, $C_{f}\left(m o l . m^{-3}\right)$ the volume concentration of analyte in solution, $N_{\text {ech }}\left(\mathrm{mol} . \mathrm{m}^{-2} . s^{-1}\right)$ the flux of analyte exchanged between the liquid phase and the solid phase, $R(m)$ the radius of a particle and $\epsilon$ the interstitial void fraction of the packed bed.

Mass balance in the solid phase The mass balance of analyte in the solid phase (that is to say the analyte bound to ligand) is:

$$
\frac{\partial C_{s}(z, t)}{\partial t}=\frac{3}{R} N_{e c h}(z, t)
$$

with $C_{s}\left(\right.$ mol. $\left.m^{-3}\right)$, the volume concentration of analyte bound to ligand. 


\section{Hydrodynamic model}

Flow through a packed bed of particles is generally represented by the axially dispersed plug flow model. $\sqrt[36]{ }$ The flux of analyte along the $z$ axis is written:

$$
N(z, t)=v C_{f}(z, t)-D_{a x} \frac{\partial C_{f}(z, t)}{\partial z}
$$

where $C_{f}$ is the analyte concentration in the liquid phase or bulk concentration. In order to take into account the fact that the liquid velocity is not uniform on the cross section of the column, the analyte convected flux $v C_{f}$ is corrected by the axial dispersion term where $D_{a x}$ is the axial dispersion coefficient $\left(\mathrm{m}^{2} \cdot \mathrm{s}^{-1}\right)$. Considering that the interstitial fluid velocity, $v$ $\left(m . s^{-1}\right)$, is uniform according to $z$ as well as the axial dispersion coefficient, the derivative is:

$$
\frac{\partial N(z, t)}{\partial z}=v \frac{\partial C_{f}(z, t)}{\partial z}-D_{a x} \frac{\partial^{2} C_{f}(z, t)}{\partial z^{2}}
$$

\section{Fluid-solid mass transfer model: the film model}

An immunoassay is not only driven by dynamic association and dissociation processes. Before binding to ligands, analytes must first be transported to the solid surface. It has been shown that when a fast analyte/ligand association rate occurs, the global association process can be limited by the transport of analyte to the solid surface. ${ }^{37 / 38}$ Similarly, if dissociation between analyte and ligand is fast, the dissociation process can be limited by the transport of analyte away from the solid surface.

When mass transport limitation cannot be avoided because of experimental constraints, a model including mass transport has to be used. $\frac{39}{} \mathrm{~A}$ simple model has been described to take into account mass transfer: the film model. The model, illustrated in Figure 2, is based on a two-step process:

- the first step is the transport of analyte from the bulk to the solid surface characterized by the mass transport coefficient $k_{c}\left(m . s^{-1}\right), \underline{40}$ 
- the second step is the binding of analyte with immobilized ligand characterized by the intrinsic association and dissociation rate constants $k_{o n}\left(m^{3} \cdot \mathrm{mol}^{-1} \cdot s^{-1}\right)$ and $k_{o f f}\left(s^{-1}\right)$, respectively.

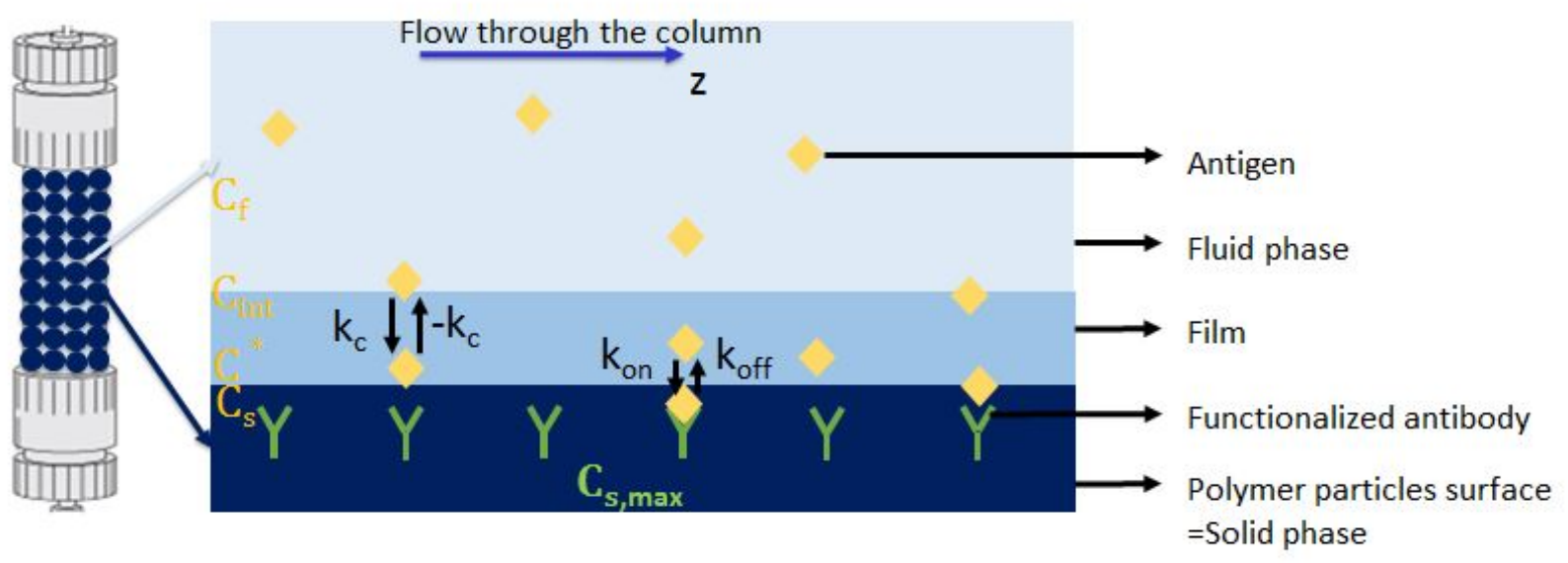

Figure 2: Diagram of mathematical model. Analyte (antigens in this work) are represented by orange diamonds in the diagram, while ligands (antibodies in this work) are represented in green.

The flux of analyte $N_{\text {ech }}\left(\mathrm{mol} . \mathrm{m}^{-2} \cdot \mathrm{s}^{-1}\right)$ as given by the film model (药) is proportional to the difference between the bulk concentration $C_{f}$ and the concentration of the fluid phase in contact with the solid surface $C_{\text {int }}\left(\right.$ mol. $\left.m^{-3}\right)$ :

$$
N_{\text {ech }}(z, t)=k_{c}\left(C_{f}(z, t)-C_{\text {int }}(z, t)\right)
$$

The Sherwood number: $S h=\frac{2 R k_{c}}{D_{m}}$ is the dimensionless group characterizing film mass transfer, $\stackrel{36}{,}$ with $D_{m}$ the analyte molecular diffusivity in the fluid phase $\left(m^{2} \cdot s^{-1}\right)$. According to Wilson and Geankoplis correlation, $\frac{36141}{1}$ for Reynolds number $\left(R e=\frac{\rho v \epsilon 2 R}{\mu}\right)$ smaller than 55 (where $\rho\left(k g \cdot m^{-3}\right)$ and $\mu\left(k g \cdot m^{-1} \cdot s^{-1}\right)$ are the fluid density and dynamic viscosity, respectively), $S h=\frac{1.09}{\epsilon} R e^{0.33} S c^{0.33}$ with $S c=\frac{\mu}{\rho D_{m}}$ the Schmidt number. The mass transport coefficient $k_{c}$ can thus be expressed as a function of volumetric fluid flow rate $f$ $\left(m^{3} \cdot s^{-1}\right)$, particle diameter $R$ and void fraction of the packed bed $\epsilon: k_{c}=\alpha \frac{1}{\epsilon} R^{\frac{-2}{3}} f^{\frac{1}{3}}$ with 
$\alpha=1.09 D_{m}^{\frac{2}{3}} S^{\frac{-1}{3}} 2^{\frac{-2}{3}}$ where $S\left(m^{2}\right)$ is the section of the chromatography column. Unlike $k_{c}, \alpha$ is the same for all experiments performed in this work and can be estimated from all experiments. It is independent of radius of particle, flow rate and void fraction of the packed bed.

\section{Kinetic model}

The simplest model for the binding of an analyte to a ligand is the 1:1 interaction model. $\underline{42}$ When equilibrium is reached, this model leads to the well known Langmuir model.

The rate of the adsorption process, $r_{a d s}\left(m o l . m^{-3} \cdot s^{-1}\right)$, can be written:

$$
r_{\text {ads }}(z, t)=k_{\text {on }} C_{\text {int }}(z, t)\left(C_{s, \max }-C_{s}(z, t)\right)
$$

The rate of the desorption process, $r_{\text {des }}\left(m o l . m^{-3} \cdot s^{-1}\right)$, can be written:

$$
r_{\text {des }}(z, t)=k_{\text {off }} C_{s}(z, t)
$$

$k_{o n}$ is the association rate constant $\left(m^{3} \cdot m^{-1} \cdot s^{-1}\right)$ and $k_{o f f}$ is the dissociation rate constant $\left(s^{-1}\right) . C_{s, \max }\left(\right.$ mol. $\left.m^{-3}\right)$ is the maximum volume concentration of analyte bound to ligand (and also the maximum volume concentration of free ligand).

\section{Equality of flows}

At this point we have three unknowns $\left(C_{f}, C_{i n t}\right.$ and $\left.C_{s}\right)$ but only two equations (the analyte mass balances in fluid and in solid). Further hypothesis need to be made. The volume of the film is very small, consequently it can be assumed that it does not accumulate analyte. We thus get:

$$
N_{e c h}(z, t) d S_{e c h}=r_{a d s} d V_{s}-r_{d e s} d V_{s}
$$

$d V_{s}$ is the volume of solid in the infinitely small column element of thickness $d z$ and 
$d S_{\text {ech }}$ the infinitesimal exchanged area between the liquid phase and the solid phase. Using equations (5), (6) and (7), $C_{\text {int }}$ can thus be expressed as a function of $C_{f}$ and $C_{s}$ :

$$
C_{\text {int }}(z, t)=\frac{C_{f}(z, t)+\frac{k_{o f f} R}{3 k_{c}} C_{s}(z, t)}{1+\frac{k_{o n} R}{3 k_{c}}\left(C_{s, \max }-C_{s}(z, t)\right)}
$$

The mass balance of free analyte in the fluid phase (1) becomes:

$$
\begin{aligned}
\frac{\partial C_{f}(z, t)}{\partial t}=-\frac{\partial N(z, t)}{\partial z} & \\
& -\frac{3 k_{c}}{R} \frac{1-\epsilon}{\epsilon}\left(C_{f}(z, t)-\frac{C_{f}(z, t)+\frac{k_{o f f} R}{3 k_{c}} C_{s}(z, t)}{1+\frac{k_{o n} R}{3 k_{c}}\left(C_{s, \text { max }}-C_{s}(z, t)\right)}\right)
\end{aligned}
$$

The mass balance of analyte in the solid phase (2) becomes:

$$
\frac{\partial C_{s}(z, t)}{\partial t}=\frac{3 k_{c}}{R}\left(C_{f}(z, t)-\frac{C_{f}(z, t)+\frac{k_{o f f} R}{3 k_{c}} C_{s}(z, t)}{1+\frac{k_{o n} R}{3 k_{c}}\left(C_{s, \max }-C_{s}(z, t)\right)}\right)
$$

\section{Change of variables and nondimensionalization}

The column model above described contains many parameters to be estimated by fitting the model to breakthrough experiments. A preliminary analysis can be performed to try to reduce the size of the optimization problem. The first idea is to formulate the model by using dimensionless variables in the liquid: $\xi=\frac{z}{L}$ and $\psi_{f}(z, t)=\frac{C_{f}(z, t)}{C_{\text {adim }}}$ where $L(m)$ is the column length and $C_{\text {adim }}\left(\right.$ mol. $\left.\mathrm{m}^{-3}\right)$ is a reference concentration. In the same way, a dimensionless variable $\frac{C_{s}(z, t)}{C_{s, \max }}$ could be used for the solid phase analyte concentration but a better choice exists by defining the following concentration $C^{*}(z, t)$ :

$$
\frac{C_{s}(z, t)}{C_{s, \max }}=\frac{k_{\text {on }}}{k_{\text {off }}} \frac{C^{*}(z, t)}{1+\frac{k_{o n}}{k_{o f f}} C^{*}(z, t)}
$$

$C^{*}(z, t)\left(\right.$ mol. $\left.m^{-3}\right)$ is the concentration of a fluid phase that would be at equilibrium 


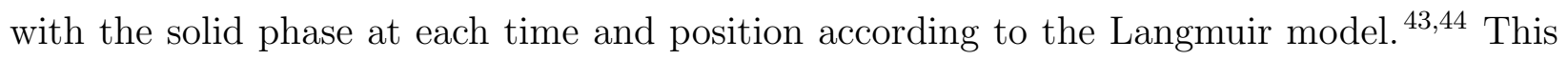
concentration can also be transformed into a dimensionless variable: $\psi^{*}(z, t)=\frac{C^{*}(z, t)}{C_{\text {adim }}}$.

From structural parameters identifiability analysis, such a change of state variable for the stationary phase representation has proved to reduce the number of independent parameters of chromatographic column models that can be theoretically estimated from a breakthrough experiment $\left(\frac{4546}{46}\right)$.

Another advantage of the change of state variable $(12)$ is that, if the initial conditions of the column correspond to an equilibrium state before the inlet step concentration is applied (this condition is generally satisfied), the entire initial concentration profiles are measured since in this case: $C^{*}(z, t=0)=C_{f}(z, t=0)=C_{f}(z=L, t=0)$. This is a great advantage since the initial equilibrium condition $\frac{C_{s}(z, t)}{C_{s, \max }}=\frac{k_{o n}}{k_{o f f}} \frac{C_{f}(z, t)}{1+\frac{k_{o n}}{k_{o f f}} C_{f}(z, t)}$ does not need to be included in the parameter estimation procedure when the initial conditions are not zero. Such non zero initial equilibrium conditions have been used for example for studying mass transfer

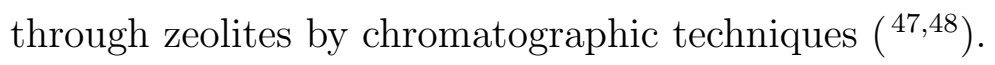

In our case, surface equilibrium is not reached and the change of state variable (12) does not lead to a decrease of the number of structurally identifiable parameters but the second advantage that is linked to the initial equilibrium conditions remains.

The mass balances in solid and liquid phases become:

$$
\begin{gathered}
\frac{\partial \psi^{*}}{\partial t}=k_{o f f}\left(1+\frac{k_{o n}}{k_{o f f}} C_{a d i m} \psi^{*}\right)^{2} \frac{\psi_{f}-\psi^{*}}{1+\frac{k_{o n}}{k_{o f f}} C_{a d i m} \psi^{*}+t_{c} k_{o n} C_{s, \max }} \\
\frac{\partial \psi_{f}}{\partial t}=-\frac{1}{t_{0}} \frac{\partial \psi_{f}}{\partial \xi}+\frac{1}{P e t_{0}} \frac{\partial^{2} \psi_{f}}{\partial \xi^{2}}-\frac{1-\epsilon}{\epsilon} \frac{k_{o n} C_{s, \max }\left(\psi_{f}-\psi^{*}\right)}{1+\frac{k_{o n}}{k_{o f f}} C_{a d i m} \psi^{*}+t_{c} k_{o n} C_{s, \max }}
\end{gathered}
$$

with $t_{0}=\frac{L}{v}=\frac{V_{f}}{f}$ (time constant characteristic of flow in the column in $s$ ), $P e=\frac{v L}{D_{a x}}$ (Peclet number) and $t_{c}=\frac{R}{3 k_{c}}=\frac{R}{3 \alpha \frac{1}{\epsilon} R^{\frac{-2}{3}} f^{\frac{1}{3}}}$ (time constant characteristic of mass transport processes in $s)$. $V_{f}$, the volume of fluid in the chromatography column $\left(\mathrm{m}^{3}\right)$ is obtained by subtracting the volume of solid obtained by weighing to the volume of the column. $P e$ 
is estimated with nonlinear least-squares fitting method from Residence Time Distribution (RTD) measurements with sodium chloride as a tracer at different flow rates. $k_{o n}, k_{\text {off }}$, $C_{s, \max }$ and $\alpha$ are the parameters to be estimated from affinity chromatography experiments.

As it can be seen in equations (13) and (14), the change of state variable (12) allows expressing the analyte flux between the bulk and the solid surface as a function of a global driving force $\psi_{f}(\xi, t)-\psi^{*}(\xi, t)$ and a global non linear mass transfer resistance $(\underline{43})$.

\section{Mathematical model of the tubing}

Mass balance The mass balance of analyte in the fluid phase in the tubes before the column is:

$$
\frac{\partial \psi_{\text {tubes }}}{\partial t}=-\frac{1}{t_{0, \text { tubes }}} \frac{\partial \psi_{\text {tubes }}}{\partial \xi_{\text {tubes }}}+\frac{1}{P e_{\text {tubes }} t_{0, \text { tubes }}} \frac{\partial^{2} \psi_{\text {tubes }}}{\partial \xi_{\text {tubes }}^{2}}
$$

with $\psi_{\text {tubes }}\left(\xi_{\text {tubes }}, t\right)$ the normalized antigen concentration in the tubes before the column, $P e_{\text {tubes }}$ the Péclet number of flow in the tubes before column, $t_{0, t u b e s}$ the time constant characteristic of flow in the tubes in $s, t_{0, \text { tubes }}=\frac{V_{\text {tubes }}}{f}$ with $V_{\text {tubes }}$ the volume of tubing before the column.

\section{Implementation of the mathematical model}

Equations (13), (14) and (15) can be numerically integrated with the following initial and boundary conditions.

\section{Initial conditions}

At the beginning of each experiment $(t=0)$, the system is considered at equilibrium. Dimensionless fluid analyte volume concentration is thus considered uniform in the whole system and equal to the first measurement of dimensionless analyte volume concentration at the outlet of the system, $\psi_{f, e x p}(t=0)$. Thus, the initial conditions considered are: 
- for the tubes preceding the column:

$$
\forall \xi_{\text {tubes }}, \psi_{\text {tubes }}\left(\xi_{\text {tubes }}, t=0\right)=\psi_{f, \exp }(t=0)
$$

- for the column:

$$
\forall \xi, \psi_{f}(\xi, t=0)=\psi^{*}(\xi, t=0)=\psi_{f, \exp }(t=0)
$$

\section{Boundary conditions}

At the inlet of the system (after the buffer valve, at the inlet of G0 tube, $\xi_{\text {tubes }}=0$ ), the dimensionless analyte concentration is considered equal to the analyte dimensionless concentration $\psi_{e}(\mathrm{t})$ in the inlet flow:

$$
\forall t, \psi_{\text {tubes }}\left(\xi_{\text {tubes }}=0^{+}, t\right)=\psi_{e}(t)
$$

At the outlet of the system (outlet of the column, $\xi_{\text {tubes }}=1$ ), the gradient concentration is assumed to be zero :

$$
\forall t, \frac{\partial \psi_{f}\left(\xi=1^{-}, t\right)}{\partial \xi}=0
$$

\section{Connection conditions}

At the boundary separating the column from tubing preceding them $\left(\xi_{\text {tubes }}=1, \xi=0\right)$, the connection conditions are:

$$
\forall t, \psi_{f}\left(\xi=0^{+}, t\right)=\psi_{\text {tubes }}\left(\xi_{\text {tubes }}=1, t\right)
$$

and:

$$
\forall t, \frac{\partial \psi_{\text {tubes }}\left(\xi_{\text {tubes }}=1^{-}, t\right)}{\partial \xi_{\text {tubes }}}=0
$$




\section{Numerical resolution}

Space discretization is needed to implement in MATLAB ${ }^{\circledR}$ the mathematical models of tubing before column and of column (1D models). The finite-difference method is used to transform Partial Differential Equation (PDE) into Ordinary Differential Equation (ODE). The obtained set of ODEs is then solved by an ODE solver in MATLAB ${ }^{\circledR}$.

\section{Parameter estimation}

Parameters of the model are estimated by minimizing the difference between experimental and simulated data with nonlinear least-squares fitting method and trust-region-reflective algorithm. The following criteria, the sum of square errors, is minimized:

$$
D(P)=\sum_{i=1}^{N_{e x p}}\left(\psi_{f, e x p}\left(t=t_{e x p, i}\right)-\psi_{f}\left(\xi=1, t=t_{e x p, i}\right)\right)^{2}
$$

$t_{e x p, i}$ are the experimental time points at which outlet concentration is measured in $s . P$ is the vector of parameter and $N_{\text {exp }}$ is the number of experimental points. From RTD experiments without chromatography column, the following vector of parameter is estimated: $P=\left(\begin{array}{c}P e_{\text {tubes }} \\ V_{\text {tubes }}\end{array}\right)$. From RTD experiments with chromatography column, the following parameter is estimated: $P=P e$. From breakthrough and purge experiments, the following vector of parameter is estimated: $P=\left(\begin{array}{c}k_{o n} \\ k_{o f f} \\ C_{s, \text { max }, \text { ground }} \\ C_{s, \text { max }, \text { notground }} \\ \alpha\end{array}\right) \cdot C_{s, \text { max }, \text { ground }}$ corresponds to the maximum volume concentration of analyte bound to ligand on ground SBC particles while $C_{s, \text { max, notground }}$ corresponds to maximum volume concentration of analyte bound to ligand on not ground SBC pellets. 
Confidence intervals of $P_{\text {estim }}$, the estimated vector of parameter, can be evaluated: $\underline{49}$

$$
P_{e s t i m, j}-t_{s t u d} \sqrt{V_{j j} \sigma^{2}}<P_{j}<P_{e s t i m, j}+t_{s t u d} \sqrt{V_{j j} \sigma^{2}}
$$

$\sigma^{2}$ is the variance and can be estimated by dividing the sum of square error by the degrees of freedom (the difference between $N_{\exp }$ and $k$ the number of parameters):

$$
\sigma^{2}=\frac{D\left(P_{e s t i m}\right)}{N_{e x p}-k}
$$

$t_{\text {stud }}$ is a variable following the Student distribution with $N_{\text {exp }}-k$ degrees of freedom and $V_{i j}$ is defined as follows:

$$
V_{i j}=\left\{\frac{\mathbf{H}^{-1}}{2}\right\}_{i j} \text { with } \mathbf{H}=\left\{\frac{\partial^{2} D\left(P_{\text {estim }}\right)}{\partial P_{i} \partial P_{j}}\right\}_{i j}
$$

where $\mathbf{H}$ is the Hessian matrix. Correlation between estimated parameters can be evaluated. $\operatorname{Corr}_{i j}$ is the correlation coefficient between $P_{e s t i m, i}$ and $P_{e s t i m, j}$ :

$$
\operatorname{Corr}_{i j}=\frac{V_{i j}}{\sqrt{V_{i i} V_{j j}}}
$$

\section{Results and discussion}

\section{Surface Plasmon Resonance results}

From Biacore T100 experiments for different FPSA concentrations $(0.625 \mathrm{nM}, 1.25 \mathrm{nM}$, $2.5 \mathrm{nM}, 5 \mathrm{nM}, 10 \mathrm{nM}$, and $20 \mathrm{nM}), k_{o n, b i a c o r e}$ and $k_{\text {off,biacore }}$ parameters are estimated to $1.4 \times 10^{3} \mathrm{~m}^{3} \cdot \mathrm{mol}^{-1} \cdot \mathrm{s}^{-1}$ and $4.0 \times 10^{-4} \mathrm{~s}^{-1}$ with standard errors $6 \times 10^{-1} \mathrm{~m}^{3} \cdot \mathrm{mol}^{-1} \cdot \mathrm{s}^{-1}$ and $5 \times 10^{-7} \mathrm{~s}^{-1}$, respectively. 


\section{Affinity chromatography results}

\section{Hydrodynamic parameter estimation}

Tubing before column hydrodynamic parameters Volume of tubing before column, $V_{\text {tubes }}$, and the Péclet number of flow in the tubes before column, $P e_{\text {tubes }}$, are estimated with nonlinear least-squares fitting method from RTD measurements with sodium chloride as a tracer at different flow rates: $V_{\text {tubes }}=1.98 \mathrm{~mL}$ and $P e_{\text {tubes }}=33 \pm 1 \%$.

Column hydrodynamic parameters $P e$ is estimated with nonlinear least-squares fitting method from RTD measurements with sodium chloride as a tracer at different flow rates: $P e=75 \pm 2 \%$ for ground SBC support and $P e=15.4 \pm 5 \%$ for not ground SBC support.

\section{Kinetic and mass transfer parameter estimation}

Breakthroughs and purges have been performed with chromatography column filled with ground SBC (6 experiments) and not ground SBC (3 experiments) at different flow rates $(0.5 \mathrm{~mL} / \mathrm{min}, 1 \mathrm{~mL} / \mathrm{min}, 2 \mathrm{~mL} / \mathrm{min}$ and $5 \mathrm{~mL} / \mathrm{min})$. The inlet concentration is $9.5 \mathrm{ng} / \mathrm{mL}$ for experiments 1 to $3,8.6 \mathrm{ng} / \mathrm{mL}$ for experiment $4,10 \mathrm{ng} / \mathrm{mL}$ for experiment $6,9.2 \mathrm{ng} / \mathrm{mL}$ experiment $7,9.4 \mathrm{ng} / \mathrm{mL}$ experiment 9 and $0 \mathrm{ng} / \mathrm{mL}$ for experiments 5 and 8 . Parameters of the model $\left(k_{o n}, k_{o f f}, C_{s, \text { max, ground }}, C_{s, \text { max }, \text { notground }}, \alpha\right)$ are estimated in one step from nine experimental curves. The concentration at the outlet of the column is simulated with this set of parameters and compared with the experimental concentration (see Figure 3 and 4 ). The estimated vector parameter with the associated $95 \%$ confidence intervals is:

$$
P_{\text {estim }}=\left(\begin{array}{c}
k_{\text {on,estim }} \\
k_{\text {off,estim }} \\
C_{s, \text { max,ground,estim }} \\
C_{s, \text { max,notground,estim }} \\
\alpha_{\text {estim }}
\end{array}\right)=\left(\begin{array}{c}
1.3 \times 10^{2} \mathrm{~m}^{3} \cdot \mathrm{mol}^{-1} \cdot \mathrm{s}^{-1} \pm 14 \% \\
1.2 \times 10^{-4} \mathrm{~s}^{-1} \pm 5 \% \\
1.7 \times 10^{-3} \mathrm{~mol} \cdot \mathrm{m}^{-3} \pm 12 \% \\
1.1 \times 10^{-3} \mathrm{~mol} \cdot \mathrm{m}^{-3} \pm 13 \% \\
1.2 \times 10^{-3} \mathrm{~m}^{\frac{2}{3}} \cdot \mathrm{s}^{-\frac{2}{3}} \pm 35 \%
\end{array}\right)
$$




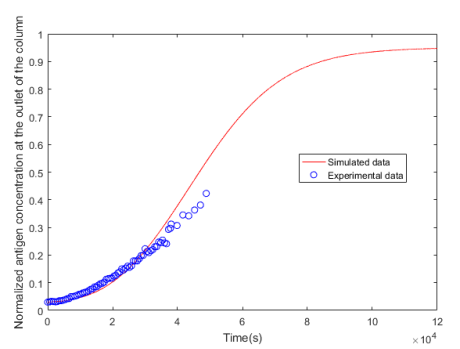

(a) Experiment 1: breakthrough $0.5 \mathrm{~mL} / \mathrm{min}$

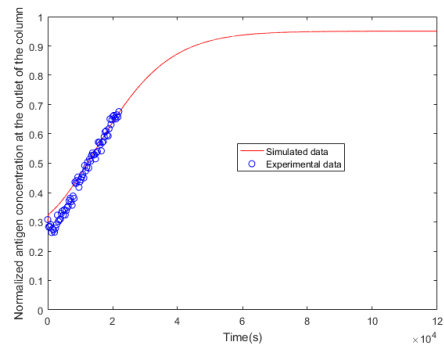

(c) Experiment 3: breakthrough $1 \mathrm{~mL} / \mathrm{min}$

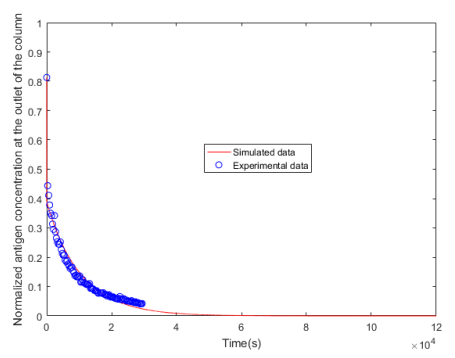

(e) Experiment 5: purge $5 \mathrm{~mL} / \mathrm{min}$

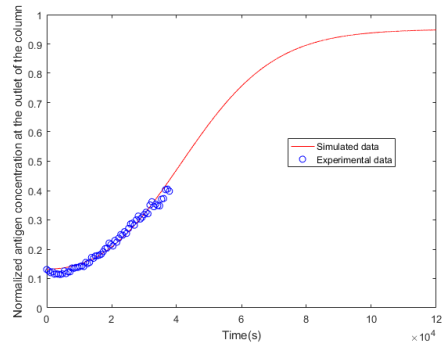

(b) Experiment 2: breakthrough $0.5 \mathrm{~mL} / \mathrm{min}$

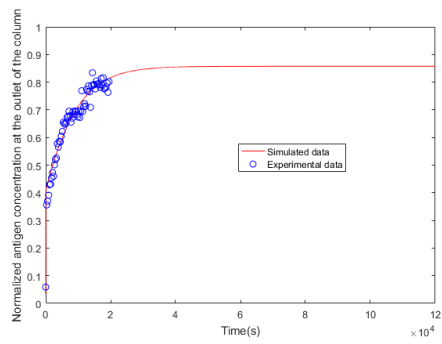

(d) Experiment 4: breakthrough $5 \mathrm{~mL} / \mathrm{min}$

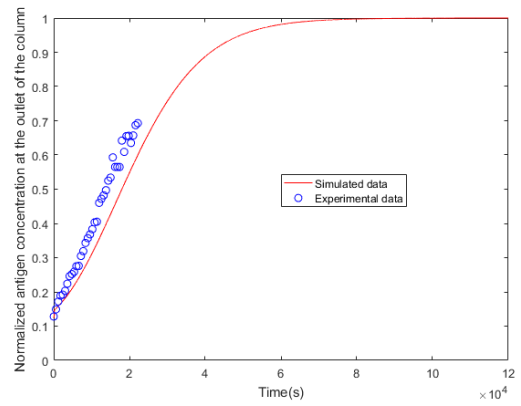

(f) Experiment 6: breakthrough $1 \mathrm{~mL} / \mathrm{min}$

Figure 3: Simulated (red line) and experimental (blue dots) normalized antigen concentration at the outlet of the system during breakthrough and purge experiments performed with a chromatography column filled with ground SBC particles. Parameters used for simulations are estimated by minimizing the difference between experimental and simulated data with nonlinear least-squares fitting method.

These estimated adsorption and desorption rate constants differ from those obtained with the BIAcore ${ }^{\circledR}$ system, suggesting that antigen dilution buffer and/or antibody immobilization support do have an impact on antibody/antigen interaction kinetics. The Figures 3 and 4 show that simulated and experimental data are close. The same adsorption and desorption 


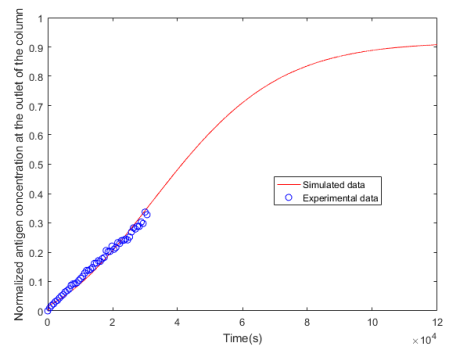

(a) Experiment 7: breakthrough $0.5 \mathrm{~mL} / \mathrm{min}$

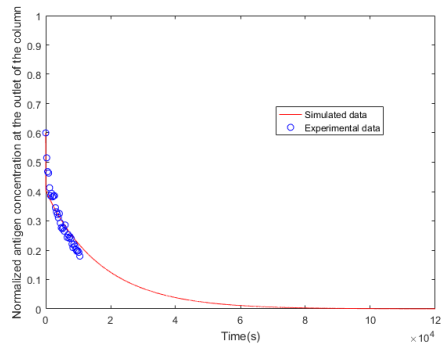

(b) Experiment 8: purge $2 \mathrm{~mL} / \mathrm{min}$

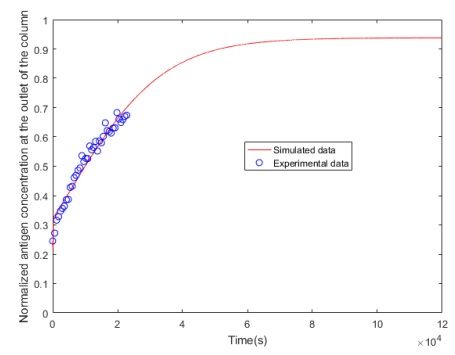

(c) Experiment 9: breakthrough $1 \mathrm{~mL} / \mathrm{min}$

Figure 4: Simulated (red line) and experimental (blue dots) normalized antigen concentration at the outlet of the system during breakthrough and purge experiments performed with a chromatography column filled with not ground SBC particles. Parameters used for simulations are estimated by minimizing the difference between experimental and simulated data with nonlinear least-squares fitting method.

constant rates enable the fitting of simulation to experimental data for different operating conditions (breakthrough and purges, different flow rates and different solid-phase sizes). With the estimation performed from the nine experiments, the magnitude of the confidence intervals is in a good range compared to that performed with only one experiment which is about $105 \%$.

Correlation between estimated parameters can be evaluated. The correlation coefficient between two estimated parameters $P_{\text {estim }, i}$ and $P_{e s t i m, j}$ is denoted: $\operatorname{Corr}_{i j}=\left(P_{i}, P_{j}\right)$. The matrix of correlation coefficients Corr $_{i j}$ obtained for the estimation from the nine experiments is 1

\footnotetext{
${ }^{1} 1$ stands for max,ground and 2 stands for max,not ground.
} 


$$
\begin{gathered}
\left(\begin{array}{ccccc}
\left(k_{o n}, k_{o n}\right) & \left(k_{o n}, k_{o f f}\right) & \left(k_{o n}, C_{s, 1}\right) & \left(k_{o n}, C_{s, 2}\right) & \left(k_{o n}, \alpha\right) \\
\left(k_{o f f}, k_{o n}\right) & \left(k_{o f f}, k_{o f f}\right) & \left(k_{o f f}, C_{s, 1}\right) & \left(k_{o f f}, C_{s, 2}\right) & \left(k_{o f f}, \alpha\right) \\
\left(C_{s, 1}, k_{o n}\right) & \left(C_{s, 1}, k_{o f f}\right) & \left(C_{s, 1}, C_{s, 1}\right) & - & \left(C_{s, 1}, \alpha\right) \\
\left(C_{s, 2}, k_{o n}\right) & \left(C_{s, 2}, k_{o f f}\right) & - & \left(C_{s, 2}, C_{s, 2}\right) & \left(C_{s, 2}, \alpha\right) \\
\left(\alpha, k_{o n}\right) & \left(\alpha, k_{o f f}\right) & \left(\alpha, C_{s, 1}\right) & \left(\alpha, C_{s, 2}\right) & (\alpha, \alpha)
\end{array}\right) \\
\left(\begin{array}{cccccc}
1 & -0.22 & -0.98 & -0.97 & -0.27 \\
-0.22 & 1 & 0.42 & 0.41 & -0.28 \\
-0.98 & 0.42 & 1 & - & 0.19 \\
-0.97 & 0.41 & - & 1 & -0.10 \\
-0.27 & -0.28 & 0.19 & -0.10 & 1
\end{array}\right)
\end{gathered}
$$

The closer to 1 or -1 the coefficient $\operatorname{Corr}_{i j}$ is, the higher the correlation between $P_{\text {estim, } i}$ and $P_{\text {estim, } j}$ is. With an estimation performed with only one experiment, the correlation coefficients are much closer to 1 (from 0.92 to 1 ) than with the estimation performed from the nine experiments. The estimation from the nine experiments with different operating conditions instead of an estimation from a unique experiment reduces the confidence intervals of the estimated parameters and the correlation between them. To reduce even more the confidence intervals and the correlation between the estimated parameters experiments should be performed with other operating conditions such as different inlet concentrations.

Figure 5 represents the partial derivative of the simulated outlet concentration with respect to the estimated parameters. It shows that for the six first experiments (with ground $\mathrm{SBC}$ ) the outlet concentration is not sensitive to parameter $\alpha$. Correlation between $k_{o n}$ and $C_{s, \max }$ is high (correlation coefficients close to 1 or -1 ). It can be seen that at the beginning of the experiments, the derivative with respect to $k_{o n}$ and to $C_{s, \max }$ are close but they differ 


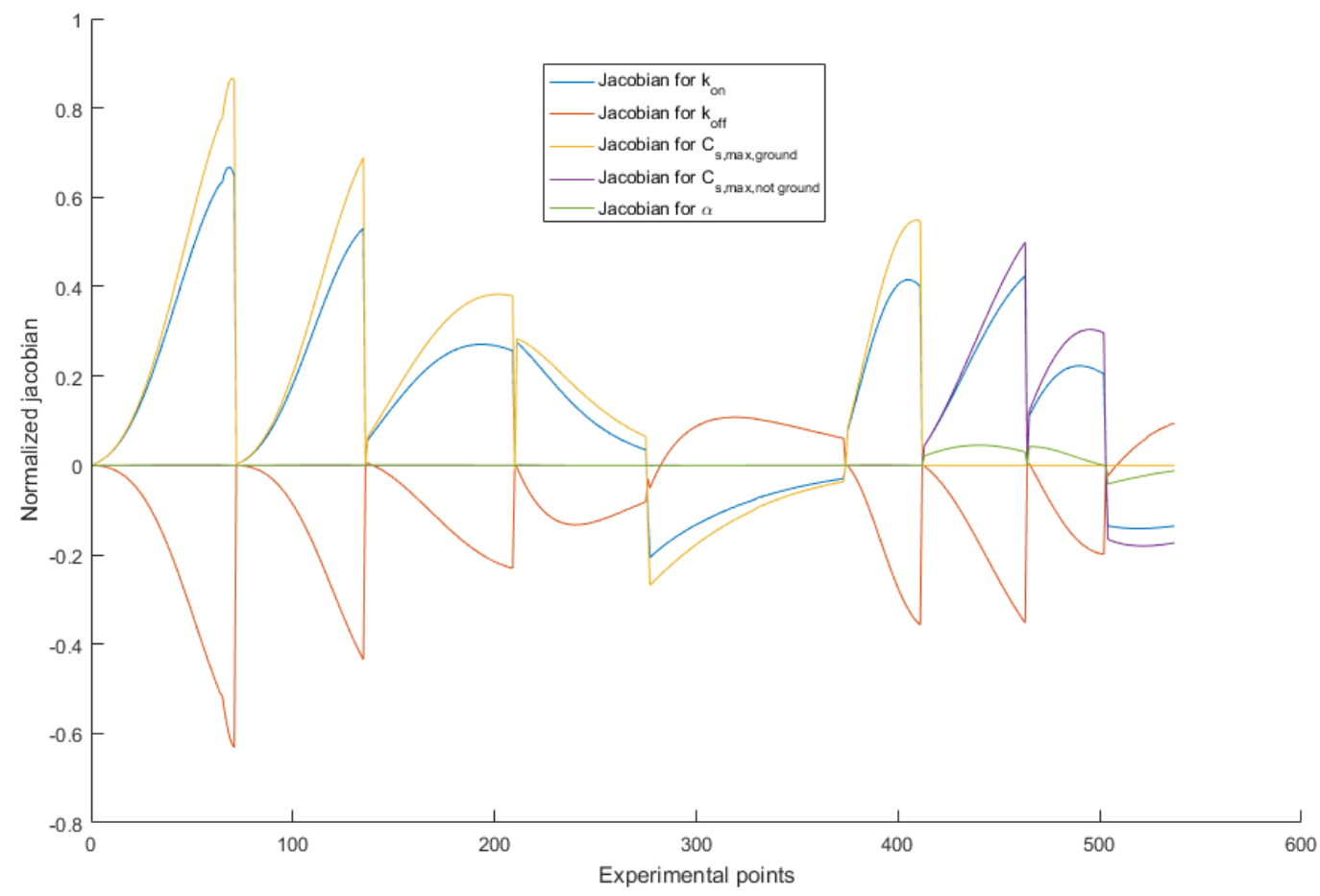

Figure 5: Partial derivative of the simulated outlet concentration with respect to the estimated parameters: $\frac{\partial \psi_{f}(\xi=1, t)}{\partial k_{o n, e s t i m}}$ (blue), $\frac{\partial \psi_{f}(\xi=1, t)}{\partial k_{o f f, e s t i m}}$ (orange), $\frac{\partial \psi_{f}(\xi=1, t)}{\partial C_{s, \text { max }, \text { ground,estim }}}$ (yellow), $\frac{\partial \psi_{f}(\xi=1, t)}{\partial C_{s, \text { max }, \text { notground,estim }}}$ (purple) and $\frac{\partial \psi_{f}(\xi=1, t)}{\partial \alpha_{\text {estim }}}$ (green). The first six experiments are experiments with ground SBC and the last three experiments are experiments with not ground SBC.

with time. By performing longer experiments, correlation between $k_{\text {on }}$ and $C_{s, \max }$ could be reduced.

The correlation between the parameters $k_{o n}$ and $C_{s, \max }$ could have been predicted as they are often close to each other in the mass balance equations (13) and (14). $k_{\text {on }}$ and $k_{\text {off }}$ are also often close to each other in the mass balance equations. Consequently, to try to reduce correlations between parameters, a new gathering of parameters is introduced and then estimated : 


$$
P_{\text {estim }}=\left(\begin{array}{c}
t_{\text {on,ground }}=\frac{1}{k_{o n} C_{s, \text { max }, \text { ground }}} \\
t_{\text {on,notground }}=\frac{1}{k_{o n} C_{s, \text { max }, \text { notground }}} \\
t_{o f f}=\frac{1}{k_{o f f}} \\
K_{o n}=\frac{k_{o n}}{k_{o f f}}
\end{array}\right)=\left(\begin{array}{c}
4.6 s \pm 3 \% \\
7.4 s \pm 3 \% \\
8.0 \times 10^{3} s \pm 5 \% \\
1.0 \times 10^{6} m^{3} . m^{-1} \pm 16 \%
\end{array}\right)
$$

With this new gathering of parameters, the parameters of the model $k_{\text {on }}, k_{\text {off }}, C_{s, \text { max }, \text { ground }}$ and $C_{s, \text { max,notground }}$ can be estimated again.

$$
\left(\begin{array}{c}
k_{\text {on,estim }} \\
k_{\text {off,estim }} \\
C_{\text {s,max,ground,estim }} \\
C_{s, \text { max }, \text { notground,estim }}
\end{array}\right)=\left(\begin{array}{c}
1.3 \times 10^{2} \mathrm{~m}^{3} . \mathrm{mol}^{-1} \cdot \mathrm{s}^{-1} \\
1.2 \times 10^{-4} \mathrm{~s}^{-1} \\
1.7 \times 10^{-3} \mathrm{~mol} . \mathrm{m}^{-3} \\
1.1 \times 10^{-3} \mathrm{~mol} . \mathrm{m}^{-3}
\end{array}\right)
$$

The same values for estimated parameters are found. However, the correlations are reduced that allows a better unicity of the estimated parameter values. The new matrix of correlation coefficients obtained for the estimation from the nine experiments is: ${ }^{2}$

$$
\left(\begin{array}{ccccc}
\left(t_{o n, 1}, t_{o n, 1}\right) & - & \left(t_{o n, 1}, t_{o f f}\right) & \left(t_{o n, 1}, K_{o n}\right) \\
- & \left(t_{o n, 2}, t_{o n, 2}\right) & \left(t_{o n, 2}, t_{o f f}\right) & \left(t_{o n, 2}, K_{o n}\right) \\
\left(t_{o f f}, t_{o n, 1}\right) & \left(t_{o f f}, t_{o n, 2}\right) & \left(t_{o f f}, t_{o f f}\right) & \left(t_{o f f}, K_{o n}\right) \\
\left(K_{o n}, t_{o n, 1}\right) & \left(K_{o n}, t_{o n, 2}\right) & \left(K_{o n}, t_{o f f}\right) & \left(K_{o n}, K_{o n}\right)
\end{array}\right)=\left(\begin{array}{cccc}
1 & - & 0.61 & -0.34 \\
- & 1 & 0.61 & -0.24 \\
0.61 & 0.61 & 1 & 0.50 \\
-0.34 & -0.24 & 0.50 & 1
\end{array}\right) .
$$

The new gathering of parameters allows the estimation of more reliable parameter values needful to compare the solid supports and the antibody/antigen interaction.

\footnotetext{
${ }^{2} 1$ stands for ground and 2 stands for not ground.
} 


\section{Conclusions}

Kinetic parameters characterizing the interactions between FPSA and an anti-FPSA antibody immobilized on two different supports were determined with SPR and affinity chromatography experiments. The adsorption and desorption rate constants obtained with the two methods differ, suggesting that antigen dilution buffer and/or antibody immobilization support have an impact on antibody/antigen interaction kinetics. The experimental tool enable the testing of different solid-phases to study their impact on antigen/antibody kinetics and consequently on immunoassay results. This is not possible with commercial systems like BIAcore ${ }^{\circledR}$. Furthermore, thanks to the experimental tool and model developed, efficient ligand concentration on solid surface can be estimated. When immobilized, ligand denaturation or conformational changes can occur. Ligands can be immobilized with their analyte binding site not well exposed to the solution phase. The estimation of properly oriented ligand concentration on different supports is of main interest because it can affect immunoassay performances. $\frac{50}{50}$

The kinetic model developed, that takes into account adsorption, desorption and mass transfer processes, helps to understand and predict the complex molecular interactions that occur in the different steps of a diagnostic immunoassay. Kinetic parameters and efficient ligand concentrations estimated through affinity chromatography and corresponding to different ligands and support could be tested with a model adapted to an immunoassay system to identify the ligands and supports which would give the best immunoassay performances.

To conclude, a mathematical model and an experimental tool to estimate its parameters with any support of interest have been developed to describe antigen/antibody interactions occurring in immunoassays. 


\section{Nomenclature}

\begin{tabular}{|c|c|}
\hline$C_{\text {adim }}$ & Reference concentration $\left(\right.$ mol. $\left.m^{-3}\right)$ \\
\hline$C_{f}$ & $\begin{array}{l}\text { Simulated volume concentration of analyte in column fluid (not bound } \\
\text { to a ligand) }\left(\text { mol. } m^{-3}\right)\end{array}$ \\
\hline$C_{f, e x p}$ & $\begin{array}{l}\text { Experimental volume concentration of analyte in solution (not bound to } \\
\text { a ligand) }\left(\mathrm{mol} . \mathrm{m}^{-3}\right)\end{array}$ \\
\hline$C_{\text {int }}$ & $\begin{array}{l}\text { Simulated volume concentration of analyte close to the interface liq- } \\
\text { uid/solid }\left(\operatorname{mol} . \mathrm{m}^{-3}\right)\end{array}$ \\
\hline$C_{s}$ & Simulated volume concentration of analyte bound to ligand $\left(\right.$ mol. $\left.m^{-3}\right)$ \\
\hline$C_{s, \max }$ & $\begin{array}{l}\text { Maximum volume concentration of analyte bound to ligand (and also the } \\
\text { maximum volume concentration of free ligand) }\left(\text { mol. }^{-3}\right)\end{array}$ \\
\hline$C_{s, \text { max }, \text { ground }}$ & $\begin{array}{l}\text { Maximum volume concentration of analyte bound to ligand on ground } \\
\text { SBC particles }\left(\text { mol. } m^{-3}\right)\end{array}$ \\
\hline$C_{s, \text { max }, \text { notground }}$ & $\begin{array}{l}\text { Maximum volume concentration of analyte bound to ligand on not } \\
\text { ground SBC pellets }\left(\text { mol. } m^{-3}\right)\end{array}$ \\
\hline$C^{*}$ & $\begin{array}{l}\text { Volume concentration of analyte in a fluid which would be in equilibrium } \\
\text { with the solid at a concentration } C_{s}\left(\mathrm{~mol} . \mathrm{m}^{-3}\right)\end{array}$ \\
\hline $\operatorname{Corr}_{i j}$ & Correlation coefficient between $P_{e s t i m, i}$ and $P_{e s t i m, j}$ \\
\hline$D_{a x}$ & Axial dispersion coefficient $\left(m^{2} \cdot s^{-1}\right)$ \\
\hline$D_{m}$ & Molecular diffusivity $\left(m^{2} . s^{-1}\right)$ \\
\hline$D(P)$ & $\begin{array}{l}\text { Sum of square errors between experimental and simulated data, criteria } \\
\text { to be minimized in nonlinear lest-squares fitting method }\end{array}$ \\
\hline$d S_{e c h}$ & $\begin{array}{l}\text { Exchanged area between the liquid phase and the solid phas ein the } \\
\text { infinitely small element of thickness } d z\left(m^{2}\right)\end{array}$ \\
\hline$d V_{s}$ & Volume of solid in the infinitely small element of thickness $d z\left(m^{3}\right)$ \\
\hline$f$ & Volumetric fluid flow rate $\left(m^{3} . s^{-1}\right)$ \\
\hline $\mathbf{H}$ & Hessian matrix \\
\hline
\end{tabular}




\begin{tabular}{|c|c|}
\hline$k$ & Number of parameters \\
\hline$k_{c}$ & Mass transport coefficient $\left(m . s^{-1}\right)$ \\
\hline$k_{o n}$ & Intrinsic association rate constant $\left(m^{3} . m o l^{-1} . s^{-1}\right)$ \\
\hline$k_{o f f}$ & Intrinsic dissociation rate constant $\left(s^{-1}\right)$ \\
\hline$L$ & Length of the chromatography column $(m)$ \\
\hline$L_{\text {tubes }}$ & Length of tubes between injection and chromatography column $(m)$ \\
\hline$N$ & $\begin{array}{l}\text { Flux of analyte along the } z \text { axis in the chromatography column } \\
\left(m o l . m^{-2} \cdot s^{-1}\right)\end{array}$ \\
\hline$N_{e c h}$ & $\begin{array}{l}\text { Flux of analyte exchanged between the liquid phase and the solid phase } \\
\left(m o l . m^{-2} \cdot s^{-1}\right)\end{array}$ \\
\hline$N_{\exp }$ & Number of experimental points \\
\hline$P$ & Vector of parameters to be estimated \\
\hline$P_{\text {estim }}$ & Estimated vector of parameters \\
\hline $\mathrm{Pe}$ & $\begin{array}{l}\text { Péclet number of the chromatography column, dimensionless group de- } \\
\text { fined as: } \frac{v L}{D_{a x}}\end{array}$ \\
\hline$P e_{\text {tubes }}$ & $\begin{array}{l}\text { Péclet number of the tubes before chromatography column, dimensionless } \\
\text { group }\end{array}$ \\
\hline$R$ & Radius of a particle in the chromatography column $(m)$ \\
\hline$R e$ & Reynolds number: $R e=\frac{\rho v \epsilon 2 R}{\mu}$, dimensionless group \\
\hline$r_{a d s}$ & Rate of the adsorption process $\left(\right.$ mol. $\left.m^{-3} . s^{-1}\right)$ \\
\hline$r_{\text {des }}$ & Rate of the desorption process $\left(\right.$ mol. $\left.m^{-3} . s^{-1}\right)$ \\
\hline$S$ & Section of the chromatography column $\left(m^{2}\right)$ \\
\hline$S c$ & Schmidt number: $S c=\frac{\mu}{\rho D_{m}}$, dimensionless group \\
\hline$S h$ & $\begin{array}{l}\text { Sherwood number: } S h=\frac{2 R k_{c}}{D_{m}} \text {, dimensionless group characterizing film } \\
\text { mass transfer }\end{array}$ \\
\hline$t$ & Time $(s)$ \\
\hline$t_{c}$ & $\begin{array}{l}\text { Time constant characteristic of mass transport processes: } t_{c}=\frac{R}{3 k_{c}}= \\
\frac{R}{3 \alpha \frac{1}{\epsilon} R^{\frac{-2}{3}} f^{\frac{1}{3}}}(s) \\
29\end{array}$ \\
\hline
\end{tabular}




$\begin{array}{ll}t_{\text {exp }, i} & \text { Experimental time points at which outlet concentration is measured } \\ t_{\text {stud }} & \text { Variable following the Student distribution with } N_{\text {exp }}-k \text { degrees of free- } \\ & \text { dom } \\ t_{0} & \text { Time constant characteristic of flow in the column: } t_{0}=\frac{L}{v}=\frac{V_{f}}{f}(s) \\ t_{0, t u b e s} & \text { Time constant characteristic of flow in the column: } t_{0, t u b e s}=\frac{V_{t u b e s}}{f}(s) \\ V_{f} & \text { Volume of fluid in the chromatography column }\left(m^{3}\right) \\ V_{i j} & \text { Element of i-th line and j-th column of matrix } \frac{\mathbf{H}^{-1}}{2} \\ V_{\text {tubes }} & \text { Volume of tubing before column }\left(m^{3}\right) \\ v & \text { Interstitial fluid velocity in chromatography column }\left(m . s^{-1}\right) \\ z & \text { Distance measured from column inlet }(m) \\ z_{t u b e s} & \text { Distance measured from injection point }(m)\end{array}$

\section{Greek letters}

$\alpha$

Parameter involved in mass transport coefficient $k_{c}=\alpha \frac{1}{\epsilon} R^{\frac{-2}{3}} f^{\frac{1}{3}}$. Unlike $k_{c}, \alpha$ is the same for all experiments performed in this work and can be estimated from all experiments. It is independent of radius of particle, flow rate and void fraction of the packed bed: $\alpha=1.09 D_{m}^{\frac{2}{3}} S^{\frac{-1}{3}} 2^{\frac{-2}{3}}$ $\left(m^{\frac{2}{3}} \cdot s^{\frac{-2}{3}}\right)$

$\epsilon$

Interstitial void fraction of the packed bed

$\mu$

Fluid dynamic viscosity $\left(\mathrm{kg} \cdot \mathrm{m}^{-1} \cdot \mathrm{s}^{-1}\right)$

$\psi_{e}$

Dimensionless inlet volume concentration of analyte

$\psi_{f}$

Dimensionless simulated volume concentration of analyte in column fluid (not bound to a ligand): $\psi_{f}=\frac{C_{f}}{C_{\text {adim }}}$

$\psi_{f, \exp }$ Experimental dimensionless volume concentration of analyte in solution (not bound to a ligand): $\psi_{f, \text { exp }}=\frac{C_{f, e x p}}{C_{\text {adim }}}$

$\psi_{\text {tubes }} \quad$ Dimensionless simulated volume concentration of analyte in tubes before column 


$$
\begin{array}{ll}
\psi^{*} & \text { Dimensionless simulated volume concentration of analyte in the fluid } \\
& \text { which would be in equilibrium with the solid: } \psi^{*}=\frac{\mathrm{C}^{*}}{C_{\text {adim }}} \\
\sigma^{2} & \text { Fluid density }\left(\mathrm{kg} \cdot \mathrm{m}^{-3}\right) \\
\xi & \text { Variance of estimated parameter } \\
\xi_{\text {tubes }} & \text { Dimensionless space variable: } \xi=\frac{z}{L} \text { for column } \\
& \text { Dimensionless space variable: } \xi_{\text {tubes }}=\frac{z_{\text {tubes }}}{L_{\text {tubes }}} \text { for tubes before column }
\end{array}
$$

\section{References}

(1) Klenin, K. V.; Kusnezow, W.; Langowski, J. Kinetics of protein binding in solid-phase immunoassays: Theory. The Journal of Chemical Physics 2005, 122, 214715.

(2) Wild, D., Ed. The immunoassay handbook: theory and applications of ligand binding, ELISA, and related techniques, 4th ed.; Elsevier: Oxford ; Waltham, MA, 2013; OCLC: ocn813855389.

(3) Sotnikov, D. V.; Zherdev, A. V.; Dzantiev, B. B. Mathematical modeling of bioassays. Biochemistry (Moscow) 2017, 82, 1744-1766.

(4) Stenberg, M.; Nygren, H. Kinetics of antigen-antibody reactions at solid-liquid interfaces. Journal of Immunological Methods 1988, 113, 3-15.

(5) Karlsson, R.; Michaelsson, A.; Mattsson, L. Kinetic analysis of monoclonal antibodyantigen interactions with a new biosensor based analytical system. Journal of Immunological Methods 1991, 145, 229-240.

(6) Chang, L.; Rissin, D. M.; Fournier, D. R.; Piech, T.; Patel, P. P.; Wilson, D. H.; Duffy, D. C. Single molecule enzyme-linked immunosorbent assays: Theoretical considerations. Journal of Immunological Methods 2012, 378, 102-115.

(7) Dinh, T. L.; Ngan, K. C.; Shoemaker, C. B.; Walt, D. R. Using Antigen-antibody 
Binding Kinetic Parameters to Understand Single-Molecule Array Immunoassay Performance. Analytical Chemistry 2016, 88, 11335-11339.

(8) Zheng, X.; Bi, C.; Li, Z.; Podariu, M.; Hage, D. S. Analytical methods for kinetic studies of biological interactions: A review. Journal of Pharmaceutical and Biomedical Analysis 2015, 113, 163-180.

(9) Butler, J. E. Solid Supports in Enzyme-Linked Immunosorbent Assay and Other SolidPhase Immunoassays. Methods 2000, 22, 4-23.

(10) Qian, W.; Yao, D.; Yu, F.; Xu, B.; Zhou, R.; Bao, X.; Lu, Z. Immobilization of antibodies on ultraflat polystyrene surfaces. Clinical Chemistry 2000, 46, 1456-1463.

(11) Gibbs, J. Immobilization Principles - Selecting the Surface http://csmedia2.corning.com/LifeSciences/media/pdf/elisa1.pdf. ELISA Technical Bulletin - Corning Incorporated Life Sciences 2001, 1, 1-8.

(12) Roach, P.; Farrar, D.; Perry, C. C. Surface Tailoring for Controlled Protein Adsorption: Effect of Topography at the Nanometer Scale and Chemistry. Journal of the American Chemical Society 2006, 128, 3939-3945.

(13) Vashist, S. K.; Dixit, C. K.; MacCraith, B. D.; O'Kennedy, R. Effect of antibody immobilization strategies on the analytical performance of a surface plasmon resonancebased immunoassay. The Analyst 2011, 136, 4431-4436.

(14) Esser, P. Activity of Adsorbed Antibodies - Application Note, Thermo Fisher Scientific. 2014.

(15) Fong, C.-C.; Wong, M.-S.; Fong, W.-F.; Yang, M. Effect of hydrogel matrix on binding kinetics of protein-protein interactions on sensor surface. Analytica Chimica Acta 2002, 456, 201-208. 
(16) Hage, D. S., Ed. Handbook of affinity chromatography, 2nd ed.; Chromatographic science series v. 92; Taylor \& Francis: Boca Raton, 2006.

(17) Rich, R. L.; Myszka, D. G. Survey of the year 2007 commercial optical biosensor literature. Journal of Molecular Recognition 2008, 21, 355-400.

(18) Yang, D.; Singh, A.; Wu, H.; Kroe-Barrett, R. Comparison of biosensor platforms in the evaluation of high affinity antibody-antigen binding kinetics. Analytical Biochemistry 2016, 508, 78-96.

(19) Jungbauer, A.; Machold, C.; Hahn, R. Hydrophobic interaction chromatography of proteins. Journal of Chromatography A 2005, 1079, 221-228.

(20) Beyer, B.; Jungbauer, A. Conformational changes of antibodies upon adsorption onto hydrophobic interaction chromatography surfaces. Journal of Chromatography A 2018, 1552, 60-66.

(21) Reverberi, R.; Reverberi, L. Factors affecting the antigen-antibody reaction. Blood Transfusion 2007,

(22) Drake, A. W.; Tang, M. L.; Papalia, G. A.; Landes, G.; Haak-Frendscho, M.; Klakamp, S. L. Biacore surface matrix effects on the binding kinetics and affinity of an antigen/antibody complex. Analytical Biochemistry 2012, 429, 58-69.

(23) Jönsson, U.; Fägerstam, L.; Ivarsson, B.; Johnsson, B.; Karlsson, R.; Lundh, K.; Löfås, S.; Persson, B.; Roos, H.; Rönnberg, I. Real-time biospecific interaction analysis using surface plasmon resonance and a sensor chip technology. BioTechniques 1991, $11,620-627$.

(24) Stenberg, E.; Persson, B.; Roos, H.; Urbaniczky, C. Quantitative determination of surface concentration of protein with surface plasmon resonance using radiolabeled proteins. Journal of Colloid and Interface Science 1991, 143, 513-526. 
(25) Oesterling, J. E. Prostate Specific Antigen: A Critical Assessment of the Most Useful Tumor Marker for Adenocarcinoma of the Prostate. The Journal of Urology 1991, 145, $907-923$.

(26) Christensson, A.; Laurell, C.-B.; Lilja, H. Enzymatic activity of prostate-specific antigen and its reactions with extracellular serine proteinase inhibitors. European Journal of Biochemistry 1990, 194, 755-763.

(27) Zhang, W. M.; Leinonen, J.; Kalkkinen, N.; Dowell, B.; Stenman, U. H. Purification and characterization of different molecular forms of prostate-specific antigen in human seminal fluid. Clinical Chemistry 1995, 41, 1567-1573.

(28) Stamey, T. A.; Yang, N.; Hay, A. R.; McNeal, J. E.; Freiha, F. S.; Redwine, E. ProstateSpecific Antigen as a Serum Marker for Adenocarcinoma of the Prostate. New England Journal of Medicine 1987, 317, 909-916.

(29) Stenman, U. H.; Leinonen, J.; Zhang, W. M. Problems in the determination of prostate specific antigen. European Journal of Clinical Chemistry and Clinical Biochemistry: Journal of the Forum of European Clinical Chemistry Societies 1996, 34, 735-740.

(30) Healthcare, G. Biacore T100 Software Handbook BR-1006-48 Edition AE. 2008.

(31) Anderson, D. J.; Walters, R. R. Equilibrium and rate constants of immobilized concanavalin A determined by high-performance affinity chromatography. Journal of Chromatography B: Biomedical Sciences and Applications 1986, 376, 69-85.

(32) Loun, B.; Hage, D. S. Chiral Separation Mechanisms in Protein-Based HPLC Columns. 2. Kinetic Studies of (R)- and (S)-Warfarin Binding to Immobilized Human Serum Albumin. Analytical Chemistry 1996, 68, 1218-1225.

(33) Yang, J.; Hage, D. S. Effect of mobile phase composition on the binding kinetics of chiral 
solutes on a protein-based high-performance liquid chromatography column:. Journal of Chromatography A 1997, 766, 15-25.

(34) Schiel, J. E.; Hage, D. S. Kinetic studies of biological interactions by affinity chromatography. Journal of Separation Science 2009, 32, 1507-1522.

(35) Brunauer, S.; Emmett, P. H.; Teller, E. Adsorption of Gases in Multimolecular Layers. Journal of the American Chemical Society 1938, 60, 309-319.

(36) Ruthven, D. M. Principles of adsorption and adsorption processes; Wiley: New York, 1984.

(37) Stenberg, M.; Stiblert, L.; Nygren, H. External diffusion in solid-phase immunoassays. Journal of Theoretical Biology 1986, 120, 129-140.

(38) Nygren, H.; Werthen, M.; Stenberg, M. Kinetics of antibody binding to solid-phaseimmobilised antigen. Journal of Immunological Methods 1987, 101, 63-71.

(39) Myszka, Kinetic analysis of macromolecular interactions using surface plasmon resonance biosensors. Current Opinion in Biotechnology 1997, 8, 50-57.

(40) Bird, R. B.; Stewart, W. E.; Lightfoot, E. N. Transport phenomena, rev. 2. ed ed.; Wiley: New York, 2007; OCLC: 255914840.

(41) Wilson, E. J.; Geankoplis, C. J. Liquid Mass Transfer at Very Low Reynolds Numbers in Packed Beds. Industrial \&6 Engineering Chemistry Fundamentals 1966, 5, 9-14.

(42) Morton, T.; Myszka, D.; Chaiken, I. Interpreting Complex Binding Kinetics from Optical Biosensors: A Comparison of Analysis by Linearization, the Integrated Rate Equation, and Numerical Integration. Analytical Biochemistry 1995, 227, 176-185.

(43) Arnold, F.; Blanch, H. Analytical affinity chromatography. Journal of Chromatography A 1986, 355, 13-27. 
(44) Boyer, P. M.; Hsu, J. T. Effects of ligand concentration on protein adsorption in dyeligand adsorbents. Chemical Engineering Science 1992, 47, 241-251.

(45) Tayakout-Fayolle, M.; Jolimaitre, E.; Jallut, C. Consequence of structural identifiability properties on state-model formulation for linear inverse chromatography. Chemical Engineering Science 2000, 55, 2945-2956.

(46) Couenne, F.; Jallut, C.; Tayakout-Fayolle, M. On minimal representation of heterogeneous mass transfer for simulation and parameter estimation: Application to breakthrough curves exploitation. Computers $\&$ Chemical Engineering 2005, 30, 42-53.

(47) Tondeur, D.; Kabir, H.; Luo, L.; Granger, J. Multicomponent adsorption equilibria from impulse response chromatography. Chemical Engineering Science 1996, 51, 3781-3799.

(48) Jolimaitre, E.; Tayakout-Fayolle, M.; Jallut, C.; Ragil, K. Determination of Mass Transfer and Thermodynamic Properties of Branched Paraffins in Silicalite by Inverse Chromatography Technique. Industrial $\&$ Engineering Chemistry Research 2001, 40, 914926.

(49) Rasmuson, A. Mathematical modeling in chemical engineering; Cambridge University Press: United Kingdom ; New York, 2014.

(50) Jung, Y.; Jeong, J. Y.; Chung, B. H. Recent advances in immobilization methods of antibodies on solid supports. The Analyst 2008, 133, 697. 


\section{For Table of Contents Only}

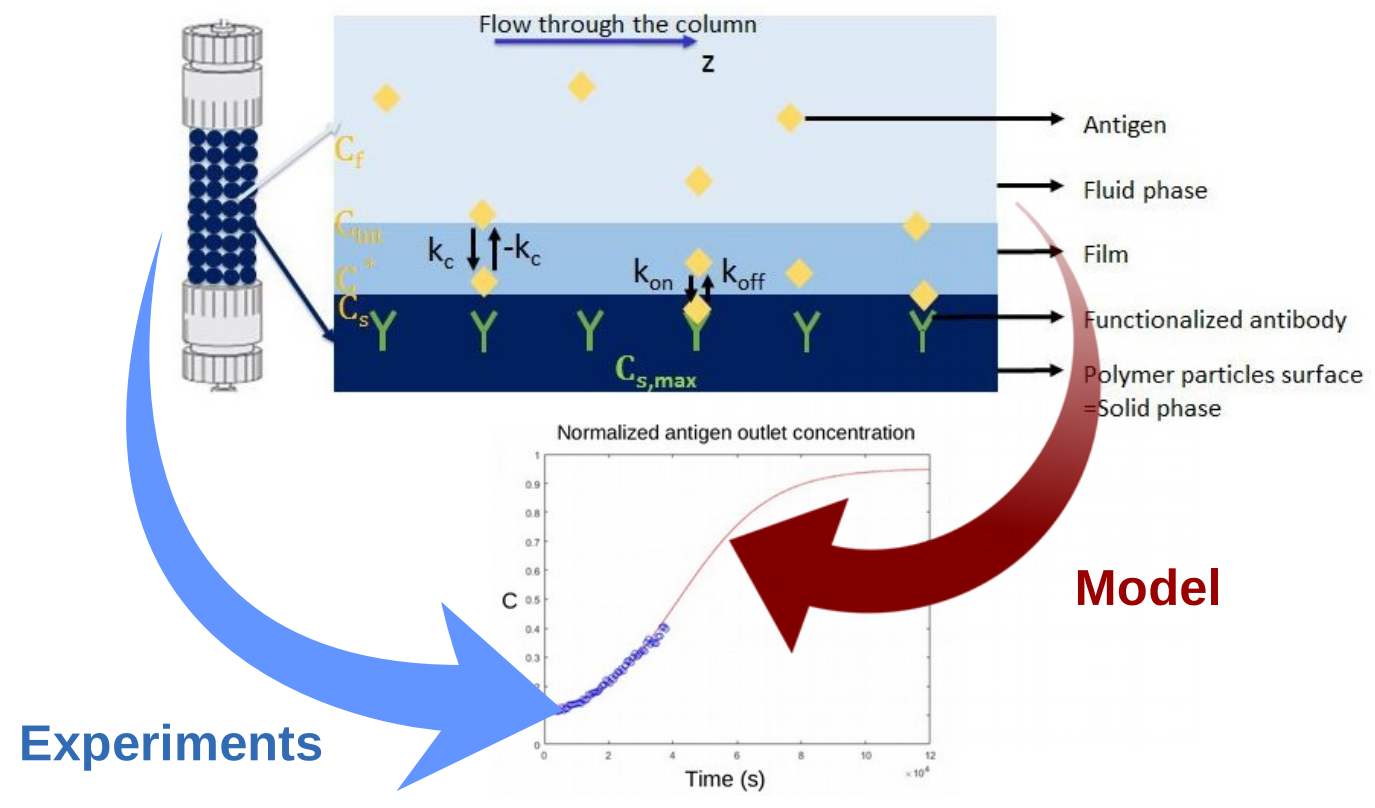

